\title{
LA DONACIÓN EN EL Código CIVIL ESPAÑOL: NOTAS SOBRE LA CAPACIDAD DE LAS PARTES*
}

\section{DONATION IN THE SPANISH CIVIL CODE: NOTES ON THE CAPACITY OF THE PARTIES}

\author{
Esther Torrelles-Torrea** \\ Fecha de recepción: 22 de abril de 2014 \\ Fecha de aceptación: 3 de mayo de 2014 \\ Disponible en linea: 1de diciembre de 2014
}

\section{Para citar este artículo/To cite this article}

\author{
Torrelles-Torrea, Esther, La donación en el Código Civil Español: notas \\ sobre la capacidad de las partes, 129 Vniversitas, 355-386 (2014). http:// \\ dx.doi.org/10.11144/Javeriana.VJ129.dcce \\ doi:10.11144/Javeriana.VJ129.dcce
}

* Trabajo original de investigación, que expone las reflexiones personales del autor sobre el tema.

** Licenciada en Derecho por la Universidad de Barcelona y doctora por la Universidad de Lleida. Profesora titular de derecho civil, Universidad de Salamanca. Consultora de derecho civil de obligaciones, persona y reales, Universitat Oberta de Catalunya, UOC. Coordinadora del doctorado Nuevas tendencias en derecho privado.Correo electrónico: etorrelles@usal.es 


\section{RESUMEN}

Se estudia la capacidad de las partes en la donación y se hace especial referencia a las legislaciones española y colombiana. En cuanto a la legislación europea, aunque el Draft Common Frame of Reference, DCFR, ha dedicado el título $\mathrm{H}$ del Libro IV al "contrato de donación", no contiene ninguna norma específica sobre la capacidad para ser donante o donatario. En las legislaciones estudiadas, respecto al donante, se incide en la necesidad de la libre disposición de los bienes y, en cuanto al donatario, se estudia la posibilidad de aceptar donaciones condicionales u onerosas, qué sucede con las donaciones realizadas a personas inhábiles y se hace referencia a las donaciones realizadas a los no nacidos.

Palabras claves: donación; capacidad; representación; personas no nacidas 


\section{ABSTRACT}

The ability of parties to donate is studied, and particular reference is made to the Spanish and Colombian legislations. With regard to the European legislation, and although the Draft Common Frame of Reference (DCFR) has dedicated the title $\mathrm{H}$ of Book IV to the "contracts for the donation of goods", it is argued that it does noy contain any specific rule on the ability to be a donor or donee. In the laws studied, regarding the donor, the paper stresses the need for the free disposal of the goods and, as to the donee, the ability to accept conditional or onerous donation. More over, it analyzes what happens to the donations made to legally incapable persons and reference is made to donations made to unborn children.

Keywords: donation; capacity; representation; unborn persons

\section{SUMARIO}

Introducción.- I. CAPAcidad del donante.- $A$. La capacidad de obrar del donante.- B. La libre disposición de los bienes por parte del donante. La representación en la donación.- II. CAPACIDAD DEL DONATARIO.- $A$. La aceptación de donaciones condicionales u onerosas: artículo 626 CC, 1460 y 1461 CCco.- B. Las donaciones hechas a personas inhábiles: artículo 628 CC y art. 1449 CCco.- C. Las donaciones a los concebidos no nacidos.BiBliogRAFía. 


\section{INTRODUCCIÓN}

El Código Civil español dedica los arts. 624 y ss a la capacidad de las partes en la donación. Aunque el Proyecto de Marco Común de Referencia para el derecho contractual europeo $\left(\mathrm{DCFR}^{1}\right)$ ha dedicado el título H del Libro IV al "contrato de donación", no contiene ninguna norma específica sobre la capacidad para ser donante o donatario ${ }^{2}$. Por tanto, partiremos del estudio sustantivo del Código Civil español ${ }^{3}$ con alguna referencia a la legislación colombiana ${ }^{4}$.

\section{CAPACIDAD DEL DONANTE}

La capacidad exigida para donar, dado que supone una disminución del patrimonio, es más estricta que la necesaria para ser donatario. Para determinar la capacidad precisa para poder realizar una donación, el art. 624 Código Civil español (en adelante, CC) advierte que "Podrán hacer donación todos los que puedan contratar y disponer de sus bienes". El precepto parte de dos requisitos para ello: capacidad para contratar (art. 1263 CC), es decir, capacidad de obrar; y libre disposición de los bienes (entre otras, Audiencia Provincial de Alicante, Sentencia SAP 425/2010, 12 de noviembre, 2011/64475).

1 Unión Europea, Draft Common Frame of Reference, DCFR, Study Group on a European Civil Code \& Research Group on EC Private Law (Acquis Group), based in part on a revised version of the Principles of European Contract Law. Disponible en: http://ec.europa.eu/justice/ policies/civil/docs/dcfr_outline_edition_en.pdf

2 El DCFR, instrumento jurídico europeo de soft law, parece configurar la donación como un contrato, con la peculiaridad de que solo contempla la donación de los bienes muebles. Para un detallado y exhaustivo estudio de la donación en el DCFR, puede consultarse ANTONIO Vaquer-Aloy, Derecho europeo de contratos, libro II y IV del Marco Común de Referencia, tomo II, 1801 y ss., Antonio Vaquer-Aloy \& Esteve Bosch-Capdevila \& María Paz SánchezGonzález, Atelier, Madrid (2012). Antonio VAquer-Aloy, La donación en España y en Europa, Reus, Madrid (2012).

3 España, Código Civil, Real Decreto del 24 de julio de 1889, 206 Boletín Oficial del Estado, BOE, 25 de julio de 1889. Texto actualizado disponible en: https://www.boe.es/buscar/act. php?id=BOE-A-1889-4763

4 Colombia, Ley 57 de 1887, por la cual se expide el Código Civil (26 de mayo de 1873). Disponible en: http://www.alcaldiabogota.gov.co/sisjur/normas/Norma1.jsp?i=39535

5 Ambos requisitos deben concurrir necesariamente, estando ante una capacidad de obrar cualificada, como han puesto de manifiesto Klaus Jochen Albiez-Dorhmann, Comentario al artículo 624 CC, en Comentarios al Código Civil, tomo IV, Rodrigo BerCovitz RodríguezCano, dir., Tirant lo Blanch, Valencia, 4787 (2013). Manuel González-Meneses García Valdecasas, La donación, en Instituciones de Derecho Privado, tomo III, vol. 2, 661, JuAN Francisco Delgado de Miguel, coord., Consejo General del Notariado y Thomson Civitas, Madrid (2004). Como sostiene Francisco Rivero-Hernández, Elementos de Derecho civil II, 
En Colombia, los requisitos son similares. Así, el art. 1444 Código Civil colombiano (en adelante, $\mathrm{CCco}$ ) advierte que "Es hábil para donar entre vivos toda persona que la ley no haya declarado inhábil" añadiendo en el art. 1445 CCco que "son inhábiles para donar los que no tienen la libre disposición de sus bienes, salvo en los casos y con los requisitos que las leyes prescriben". Esta aptitud para donar debe tenerse en el momento de hacer la donación ${ }^{6}$.

Respecto al donante, el Marco Común de Referencia (DCF) contempla la posibilidad de que pueda serlo un empresario (art. IV.H.-2:102(b) DCFR) ${ }^{7}$.

Derecho de obligaciones, vol. II, Contratos y cuasicontratos. Delito y cuasidelito, 91, José LuIS Lacruz-Berdejo, Francisco de Asís Sancho-Rebullida, Agustín Luna-Serrano \& Francisco Rivero-Hernández, Dykinson, Madrid (2009), "parece que el primer término apunta a la capacidad negocial (Cfr. S. 21 de diciembre de 1982), y el segundo, prescindiendo de cuestiones de capacidad, al poder de disposición, en sentido amplio".

En todo caso, como pone de manifiesto Pedro de Pablo-Contreras, Comentario al art. 624 CC, en Código Civil comentado, vol. II, 112, Ana Cañizares-Laso, Pedro de Pablo-Contreras, Francisco Javier Orduña-Moreno, Rosario Valpuesta-Fernández, dirs., Civitas-Thomson Reuters, Cizur Menor, Pamplona (2011), el art. 624 al exigir estos dos requisitos, en la inicial perspectiva de la redacción originaria de este precepto, todo indica que lo que se pretendía "era considerar la declaración de voluntad del donante como un acto personalísimo, que este debía realizar siempre por sí, lo que limitaba ampliamente la aptitud subjetiva o capacidad para donar. Sin embargo, desde un primer momento, la doctrina y la jurisprudencia matizaron razonablemente tal planteamiento restrictivo, y hoy existen razones aún más poderosas para rectificarla".

6 Manuel Albaladejo-García, Comentario al artículo 624 CC, en Comentarios al Código Civil y Compilaciones forales, tomo VIII, vol. 2, Artículos 618 a 656 del Código Civil, 101, Manuel Albaladejo, dir., Manuel Albaladejo-García \& Silvia Díaz-Alabart, coment., Revista de Derecho Privado, Madrid (1986). Manuel Albaladejo-García considera que si se ofrece primero donar y después se acepta en escritura separada, el momento en que debe tenerse aptitud para donar es desde el momento en que se ofrece la donación y debe conservarse hasta su conclusión. En el mismo sentido, Manuel Albaladejo-García \& Silvia Díaz-Alabart, La donación, 105-106, Centro de Estudios, Colegio de Registradores de la Propiedad, Mercantiles y de Bienes Muebles de España, Madrid (2006). Lucía Costas-Rodal, Contrato de donación, en Tratado de contratos, tomo II, 2166, n. 1532, Rodrigo Bercovitz Rodríguez-Cano, dir., Tirant lo Blanch, Valencia (2009), considera que el donante debe tener capacidad y poder de disposición durante todo el proceso de donación, desde que emana su declaración de voluntad hasta que se perfecciona, incluyendo el período intermedio y la pérdida de la capacidad extinguirá la oferta de donación, oferta que no revive por más que el donante recupere la capacidad. En contra, José María Manresa y Navarro, Comentarios al Código Civil español, V, 119, Pascual Marín-Pérez, corrección, aumento y puesta al día, Reus, Madrid (1972).

7 El DCFR establece unas excepciones a los requisitos de forma, por lo que hay donaciones válidas sin requerir solemnidad alguna. Así, el artículo IV.H.-2:102 manifiesta que no se aplica el art. IV.H.-2:101 referente a la necesidad de forma: b) si la donación la realiza un empresario. Se trata de actos realizados dentro de la actividad empresarial del donante y se consideran libres de formalidades; no es precisa la forma escrita. No hay en el Derecho español una norma similar y ciertas donaciones de muestras gratuitas realizadas por empresarios pueden encontrar en las liberalidades de uso un mecanismo para sostener su validez, pese a incumplir las exigencias formales impuestas a la donación en el Derecho español. Al respecto, ANTONIO VAQuer-Aloy, La donación en España y en Europa, Reus, Madrid, 27, 69 y ss., 74 (2012). 


\section{A. La capacidad de obrar del donante}

En una primera aproximación supone que, si la donación implica disponer de bienes y derechos, solo podrán realizarla los titulares de dichos bienes y derechos que a su vez tengan plena capacidad de obrar, es decir, los mayores de edad del artículo $322 \mathrm{CC}^{8}$, lo que excluiría los menores no emancipados, los incapacitados judicialmente, si la sentencia de incapacitación así lo determina (art. 760.1 de la Ley de Enjuiciamiento Civil, LEC; ${ }^{9}$ Sentencia del Tribunal Supremo STS 956/2011, 5 de enero de 2012, Repertorio de Jurisprudencia RJ 2012 305; la legislación colombiana usa la expresión "persona hábil")". Puede consultarse en este sentido, la Sentencia del Tribunal Supremo STS 145/2006 14 de febrero, Repertorio de Jurisprudencia RJ 20061887, en la que se declara nula una donación por falta de capacidad del donante al sufrir Alzheimer, o la Sentencia del Tribunal Supremo STS 549/2007 4 de mayo, Repertorio de Jurisprudencia RJ 2007\2819, en la que también se declara nula una donación realizada por un donante con facultades volitivas e intelectuales disminuidas.

La donación que haga un donante con falta de capacidad natural, será nula, pero en los demás casos, la falta de aptitud para contratar o disponer de los bienes en el donante supondrá la anulabilidad (art. 40.7 Ley Concursal española, LC) ${ }^{11}$.

Sin embargo, hay casos concretos en los cuales la capacidad para donar por parte de determinadas personas queda sometida a unas reglas especiales:

a. Patria potestad: para donar bienes inmuebles, establecimientos mercantiles o industriales, objetos preciosos y valores mobiliarios

8 Ana María Casanovas-I-Mussons, De las personas que pueden hacer donaciones: la capacidad de obrar y el poder de disposición del donante, en Libro homenaje al profesor Manuel AlbaladejoGarcía, tomo I, 857-876, 859, José Manuel GonzÁlez-Porras \& Fernando Pedro MéndezGonzÁlez, Universidad de Murcia, Colegio de Registradores de la Propiedad, Mercantiles y de Bienes Muebles de España, Murcia, Madrid (2004).

9 España, Ley 1/2000 o Ley de Enjuiciamiento Civil, LEC, 7 Boletín Oficial del Estado, BOE, 8 de enero de 2000. Disponible en: https:/www.boe.es/buscar/act.php?id=BOE-A-2000-323

10 Manuel Albaladejo-García, Comentario al art. 624 CC, en Comentario del Código Civil, tomo I, 1590, Ministerio de Justicia, Madrid (1993).

11 Pedro de Pablo-Contreras, Comentario al art. 624 CC, en Código Civil comentado, vol. II, 113, Ana Cañizares-Laso, Pedro de Pablo-Contreras, Francisco Javier Orduña-Moreno, Rosario Valpuesta-Fernández, dirs., Civitas-Thomson Reuters, Cizur Menor, Pamplona (2011). España, Ley 22/2003 o Ley Concursal española, 164 Boletín Oficial del Estado, BOE, 10 de julio de 2003. Disponible en: https://www.boe.es/buscar/act.php?id=BOE-A-2003-13813 
de que los hijos sean titulares, los padres precisarán que exista causa justificada de utilidad o necesidad y previa autorización del Juez del domicilio, con audiencia del Ministerio Fiscal (art. 166.1 CC). La donación se autorizará solo si revierte en beneficio del menor o si se trata de una donación remuneratoria ${ }^{12}$. En Colombia el art. 304 del Código Civil también prohíbe a los padres realizar donaciones de los bienes de los hijos, excepto si cumplen la normativa referente a los tutores y curadores.

b. El tutor, para disponer a título gratuito de los bienes o derechos del tutelado, necesita la autorización judicial (art. 271.9 CC y 491 $\mathrm{CCco}$, aunque este último es más estricto y se limita la autorización judicial a ciertos supuestos).

c. El hijo mayor de dieciséis años puede donar los bienes que adquiera con su trabajo o industria (emancipados por vida independiente), pero, dado que se trata de un acto que excede de la administración ordinaria, precisará del consentimiento de sus padres o tutores, pero sin necesidad de autorización judicial (art. 164.3 CC).

d. El emancipado o habilitado de edad, si pretende donar bienes inmuebles, establecimientos mercantiles o industriales u objetos de extraordinario valor, necesitará el consentimiento de sus padres, tutor o del curador, en ausencia de aquellos (art. $323 \mathrm{CC}$; $487 \mathrm{CCco})^{13}$. Si se trata de donaciones de bienes distintos pueden hacer dichas donaciones por acto propio.

e. El incapacitado sujeto a curatela y el pródigo, en función de lo que determine la sentencia de incapacitación o prodigalidad, necesitarán el consentimiento del curador (arts. 271.9, 286.3, 289, 290 CC; 760.3 LEC; 487 CCco).

f. Los cónyuges, si quieren disponer a título gratuito de bienes gananciales, deben prestar ambos su consentimiento, aunque cada uno de ellos puede realizar con bienes gananciales liberalidades de uso (art. $1378 \mathrm{CC}$ ). Entre ellos pueden transmitirse por cualquier título bienes y derechos (1323 CC, art. 1463 CCco). Si uno de los cónyuges es menor de edad puede donar los bienes

12 Lucía Costas-Rodal, Contrato de donación, en Tratado de contratos, tomo II, 2165, n. 1525, Rodrigo Bercovitz Rodríguez-Cano, dir., Tirant lo Blanch, Valencia (2009).

13 Este consentimiento implica en realidad un asentimiento. LuIs PuIG-Ferriol, Comentario al artículo 323 CC, en Comentario del Código Civil, 2 ed., 885, Ministerio de Justicia, Madrid (1993). 
comunes, si el otro cónyuge es mayor de edad y concurre el consentimiento de ambos; si el otro cónyuge es también menor, además, se precisará del consentimiento de los padres o tutores de uno y otro (art. $324 \mathrm{CC}$ ).

g. Las personas jurídicas privadas que tengan una finalidad lucrativa (sociedades civiles o mercantiles) podrán realizar determinados actos con carácter de liberalidad, aunque sean contrarios al fin de lucro, si benefician indirectamente a la sociedad (por ejemplo, regalos propagandísticos), o si se pretende remunerar en cuantía no exorbitante ciertos servicios prestados no exigibles legalmente, o se hace por un comportamiento de solidaridad o por otros motivos igualmente atendibles (Resolución 2 de febrero de 1966) sobre la donación de un piso por una Sociedad Anónima a un empleado para recompensarle de sus servicios). Las personas jurídicas cuyo fin institucional sea la beneficencia tienen capacidad para realizar donaciones ${ }^{14}$. Por tanto, las personas jurídicas sí pueden realizar donaciones (el art. 624 CC no las excluye, ni el art. 1444 CCco), aunque puede haber razones por las cuales no puedan hacerlo, por ejemplo, por el fin que persiguen, o porque lo prohíban sus estatutos, pero el motivo no es el artículo $624 \mathrm{CC}^{15}$.

h. Los herederos del ausente no pueden disponer a título gratuito de los bienes heredados hasta cinco años después de la declaración de fallecimiento (art. $196 \mathrm{CC}$ ).

i. Los concursados, en caso de concurso de acreedores y si este es voluntario, dado que conservan la facultad de disposición

14 La doctrina no es unánime en otorgar capacidad de donar a las personas jurídicas. En todo caso, no hay ninguna regla de incapacidad de la persona jurídica para hacer donaciones, dependiendo de lo que determinen sus estatutos (Francisco Rivero-Hernández, Elementos de Derecho civil II, Derecho de obligaciones, vol. II, Contratos y cuasicontratos. Delito y cuasidelito, 4 ed., 91, José Luis Lacruz-Berdejo, Francisco de Asís Sancho-Rebullida, Agustín Luna-Serrano \& Francisco Rivero-Hernández, Dykinson, Madrid (2009). Luis Díez-Picazo y Ponce de León \& Antonio Gullón-Ballesteros, Sistema de Derecho civil, vol. 2, tomo 2, Tecnos, Madrid, 78 (2012). José Manuel Lete del Río \& Javier Lete-Achirica, Derecho de obligaciones, vol. II, 290, Aranzadi, Cizur Menor, Navarra (2006).

15 Manuel Albaladejo-García \& Silvia Díaz-Alabart, La donación, 122, Centro de Estudios, Colegio de Registradores de la Propiedad, Mercantiles y de Bienes Muebles de España, Madrid (2006). Lucía Costas-Rodal, Contrato de donación, en Tratado de contratos, tomo II, 2166, n. 1530, Rodrigo Bercovitz Rodríguez-Cano, dir., Tirant lo Blanch, Valencia (2009). Klaus Jochen Albiez-Dorhmann, Comentario al artículo 624 CC, en Comentarios al Código Civil, tomo IV, 4790, Rodrigo Bercovitz Rodríguez-Cano, dir., Tirant lo Blanch, Valencia (2013). Todos ellos analizan con más detalle la capacidad de donar de la Iglesia, la Administración general del Estado o las entidades locales. 
sobre sus bienes, pueden donar pero con la autorización o conformidad de los administradores concursales. Sin embargo, si el concurso es necesario, no tienen dichas facultades dispositivas y les sustituyen los administradores concursales (art. 40 LC) ${ }^{16}$.

Si en todos estos supuestos se realiza la donación por parte de la persona que no puede, el acto adolecerá de distinta invalidez. Así, será nula la donación realizada por quien carece de capacidad natural; o anulable, por ejemplo, a instancia del propio curador o de la persona sujeta a curatela, cuando salga de ella, la donación realizada sin la intervención del curador.

Puede concluirse que actualmente todas las personas pueden donar, ya sean ellas mismas o con la asistencia o intervención del

16 Artículo 40 Ley concursal. Facultades patrimoniales del deudor:

1. En caso de concurso voluntario, el deudor conservará las facultades de administración y disposición sobre su patrimonio, quedando sometido el ejercicio de estas a la intervención de los administradores concursales, mediante su autorización o conformidad.

2. En caso de concurso necesario, se suspenderá el ejercicio por el deudor de las facultades de administración y disposición sobre su patrimonio, siendo sustituido por los administradores concursales.

3. No obstante lo dispuesto en los apartados anteriores, el juez podrá acordar la suspensión en caso de concurso voluntario o la mera intervención cuando se trate de concurso necesario. En ambos casos, deberá motivarse el acuerdo señalando los riesgos que se pretendan evitar y las ventajas que se quieran obtener.

4. A solicitud de la administración concursal y oído el concursado, el juez, mediante auto, podrá acordar en cualquier momento el cambio de las situaciones de intervención o de suspensión de las facultades del deudor sobre su patrimonio.

El cambio de las situaciones de intervención o de suspensión y la consiguiente modificación de las facultades de la administración concursal se someterá al régimen de publicidad de los artículos 23 y 24.

5. En caso de concurso de la herencia, corresponderá a la administración concursal el ejercicio de las facultades patrimoniales de administración y disposición sobre el caudal relicto, sin que pueda cambiarse esta situación.

6. La intervención y la suspensión se referirán a las facultades de administración y disposición sobre los bienes, derechos y obligaciones que hayan de integrarse en el concurso y, en su caso, a las que correspondan al deudor de la sociedad o comunidad conyugal.

El deudor conservará la facultad de testar, sin perjuicio de los efectos del concurso sobre la herencia.

7. Los actos del deudor que infrinjan las limitaciones establecidas en este artículo solo podrán ser anulados a instancia de la administración concursal y cuando esta no los hubiese convalidado o confirmado. Cualquier acreedor y quien haya sido parte en la relación contractual afectada por la infracción podrá requerir de la administración concursal que se pronuncie acerca del ejercicio de la correspondiente acción o de la convalidación o confirmación del acto. La acción de anulación se tramitará, en su caso, por los cauces del incidente concursal y caducará, de haberse formulado el requerimiento, al cumplirse un mes desde la fecha de este. En otro caso, caducará con el cumplimiento del convenio por el deudor o, en el supuesto de liquidación, con la finalización de esta.

Los referidos actos no podrán ser inscritos en registros públicos mientras no sean confirmados o convalidados, o se acredite la caducidad de la acción de anulación o su desestimación firme. 
curador, de los padres o del defensor judicial en los casos que se ha visto que es necesario, o por medio de sus representantes legales cumpliendo estos los requisitos legales previstos (necesidad de autorización judicial).

\section{B. La libre disposición de los bienes por parte del donante. La representación en la donación}

La libre disposición de los bienes por parte del donante supone la facultad de actuar sobre sus derechos patrimoniales; la facultad de disponer gratuitamente de la clase de bienes que se donan. Manuel Albaladejo-García manifiesta que el artículo $624 \mathrm{CC}$ no exige de por sí disponibilidad de los bienes concretos que se donen, ni disponibilidad plena por el donante de toda clase de bienes, sino solo disponibilidad de la clase de bienes que se donen. Así, un menor emancipado puede dar bienes muebles que no sean de extraordinario valor (art. 323.1 CC) pues son bienes de la clase que sí puede donar y tiene pues libre disposición sobre ellos. Lo que permite el Código Civil por medio de su artículo 624 es disponer de cierta clase de bienes sin distinguir, como regla, si se dispone de ellos a título oneroso o gratuito. No se exige plena disponibilidad de sus bienes en el sentido de que, como la donación es un acto que merma el patrimonio del donante y le perjudica, solo debe ser permitido donar a quien tiene libertad total de disponer y no a quien la tiene limitada, aunque por título oneroso pudiese disponer de los bienes que no se le permiten donar. En este sentido, como apuntábamos, un menor emancipado podrá por sí solo donar bienes muebles que no sean de extraordinario valor, ya que solo se le veda la disponibilidad de bienes inmuebles o establecimientos mercantiles o industriales u objetos de extraordinario valor (art. $323 \mathrm{CC}$ ). Por tanto, se permite donar a quienes no tienen plena y absoluta capacidad de disposición ${ }^{17}$.

Hay que advertir que es posible que los bienes se donen por el propio donante o por medio de su representante, lo que supone

17 Manuel Albaladejo-García, Comentario al art. 624 CC, en Comentario del Código Civil, tomo I, 98, Ministerio de Justicia, Madrid (1993). En el mismo sentido en Manuel Albaladejo-García \& Silvia Díaz-Alabart, La donación, 101-103, Centro de Estudios, Colegio de Registradores de la Propiedad, Mercantiles y de Bienes Muebles de España, Madrid (2006). 
tener legitimación para donar bienes de titularidad ajena. Es decir, al tratarse de un acto gratuito quien no puede enajenar no puede donar, pero la persona capaz puede donar por sí misma o por medio de representante. En el caso en que sea el representante el que actúa, al ser un acto de riguroso dominio es indispensable que haya un mandato expreso o especial para ello $^{18}$, o bien un poder general y bastante, con límites o sin ellos (art. $1713 \mathrm{CC}$; Resolución 5 de agosto de 1907$)^{19}$. Es decir, la atribución de donar debe ser de forma específica, ya sea de forma expresa o de modo que haya seguridad que se quiso conferir dicha facultad. Además, a veces, existen ciertas cautelas como la necesidad de que el representante disponga también de autorización judicial. En principio, el negocio de apoderamiento carece de la necesidad de forma solemne, aunque en caso de donación de inmuebles, por ejemplo, debería constar en escritura pública por razones de seguridad jurídica. En cuanto a la legitimación para donar bienes ajenos en nombre de su titular debe ser otorgada por el propio donante.

En la jurisprudencia también se ha generado la duda de si los representantes voluntarios, es decir, mandatario o apoderado, pueden realizar donaciones en virtud de un mandato o poder expreso dada la remisión establecida en el artículo 621 CC. La jurisprudencia apoya esta posibilidad siempre que haya mandato expreso o especial (al respecto Sentencia del Tribunal Supremo STS 193/2001 6 de marzo, Repertorio de Jurisprudencia RJ 2001\3933; 354/2008 16 de mayo, Repertorio de Jurisprudencia RJ 200814137). Si el poder no es claro, abusivo o extralimitado, la jurisprudencia deniega su

18 Como pone de manifiesto Isabel González-Pacanowska, Apoderamiento y donación (Mandato general de donar cui voles e quid voles), en Estudios Jurídicos en Homenaje a Vicente L. Montés-Penadés, 1273-1289, 1289, Francisco de Paula Blasco-Gascó, coord., Tirant lo Blanch, Valencia (2011), este poder expreso y especial supone que está delimitada de forma precisa la voluntad liberal del donante en cuanto a su objeto y en cuanto a los beneficios y debe ser suficiente para juzgar ex ante el margen de discrecionalidad del mandatario.

19 José Manuel Lete del Río \& Javier Lete-Achirica, Derecho de obligaciones, vol. II, 289, Aranzadi, Cizur Menor, Navarra (2006). En todo caso, Francisco Rivero-Hernández, Elementos de Derecho civil II, Derecho de obligaciones, vol. II, Contratos y cuasicontratos. Delito y cuasidelito, 91, José Luis Lacruz-Berdejo, Francisco de Asís Sancho-Rebullida, Agustín Luna-Serrano \& Francisco Rivero-Hernández, Dykinson, Madrid (2009), afirma que "es harto improbable que quepa otorgar un poder general para donar, teniendo en cuenta el carácter intuitu personce de la donación (...) Opuestamente cabe confiar al representante la realización de donaciones singulares cuyas circunstancias se hallen bien determinadas, y tal parece el criterio de la R. 5 agosto 1907”. 
validez (Sentencia del Tribunal Supremo STS 505/2009, 30 de junio, Repertorio de Jurisprudencia RJ 2009\4764) ${ }^{20}$.

\section{CAPACIDAD DEL DONATARIO}

Se trata de determinar ahora quién puede aceptar una donación. El Código Civil lo regula en cuatro preceptos: artículo 625: capacidad para ser donatario; artículo 626: capacidad del donatario en las donaciones condicionales u onerosas; artículo 627: las donaciones a favor de los concebidos no nacidos y el artículo 628: donaciones realizadas a personas inhábiles, el Código Civil de Cataluña, CC$\mathrm{Cat}^{21}$, lo regula en un solo precepto: 531-21 con alguna peculiaridad.

Según el artículo $625 \mathrm{CC}$, "podrán aceptar donaciones todos los que no estén especialmente incapacitados por la ley para ello"22. La regulación colombiana nos advierte en su art. 1446 que "es capaz de recibir entre vivos toda persona que la ley no ha declarado incapaz". Si se defiende que la donación no es un contrato, sorprende que este artículo se refiera a la aceptación de la misma. Lo que sucede es que la aceptación del donatario no se vincula a la validez de la donación, sino que simplemente provoca que esta se vuelva irrevocable y determina el momento de la adquisición de la propiedad o el derecho real sobre el bien objeto de la donación por el donatario. Sin embargo, esta aceptación se produce una vez el acto dispositivo ya se ha completado, no altera la unilateralidad de la donación, puesto que el donatario no interviene en la formación y perfección de la donación ${ }^{23}$.

En todo caso, como premisa hay que advertir que la "capacidad" para aceptar donaciones es diferente a la "legitimación" para

20 Para más detalle, Antonia Nieto-Alonso, Comentario a los artículos 624 a 629 CC, en Comentarios al Código Civil, 735, Andrés Domínguez-Luelmo, dir., Lex Nova, Valladolid (2010).

21 Cataluña, Código Civil de Cataluña. Disponible en: http://civil.udg.es/normacivil/cat/ccc/ES/ Index.htm

22 El Código Civil solo se encarga de la capacidad necesaria para aceptar donaciones, pero no advierte nada sobre la capacidad para repudiar las donaciones. Según KLAus JocheN Albiez-Dorhmann, Comentario al artículo 624 CC, en Comentarios al Código Civil, tomo IV, 4804-4805, Rodrigo Bercovitz Rodríguez-Cano, dir., Tirant lo Blanch, Valencia (2013), para rechazar la donación bastaría tener capacidad de obrar suficiente, pero del artículo 271.4 CC puede deducirse que se exige la misma capacidad para contratar con lo que debe acudirse al artículo $1263 \mathrm{CC}$.

23 Antonio Vaquer-Aloy, Derecho civil de Cataluña. Derechos reales, 72, Pedro del PozoCarrascosa, Antonio Vaquer-Aloy \& Esteve Bosch-Capdevila, Marcial Pons, Madrid, Barcelona, Buenos Aires, São Paulo (2012). 
aceptarlas. Así, en relación con la validez de la aceptación se hace referencia a la capacidad para aceptar y en relación con la eficacia de la aceptación se considera la legitimación para aceptar. Esta legitimación siempre corresponde al donatario ya que se la atribuye el donante al designarlo donatario. Pero a veces, puede corresponder a otras personas. Así, los artículos 627, 630 y 631 CC contemplan la posible disociación entre el donatario y el aceptante en nombre de aquel $^{24}$. Además, hay normas que establecen determinadas prohibiciones para convertirse en donatario; en tales casos se carece de legitimación para aceptarlas. Es el caso del art. $221 \mathrm{CC}$, que prohíbe al tutor recibir donaciones de su tutelado.

La capacidad del donatario es mucho más amplia que la del donante, lo cual es lógico dado que supone un enriquecimiento para él, un acto cuya eficacia es meramente beneficiosa, por lo que la capacidad natural resulta suficiente para que el donatario menor o incapacitado pueda aceptar la donación por sí mismo o por sí solo, sin la intervención de sus legítimos representantes ${ }^{25}$. Así pues, puede ser donatario cualquier persona que no esté incapacitada para ello, como sería el caso de una persona sin capacidad natural, en cuyo caso deberían actuar los representantes legales sustituyéndola (Resolución de la Dirección General de los Registros y del Notariado RDGRN 3 de marzo de 1989 [Repertorio de Jurisprudencia RJ 1989/2380]), o una persona que actúa en nombre de una persona jurídica sin tener legitimación para ello (SSTS 6 de julio de 1985 [Repertorio de Jurisprudencia RJ 1985/4132], 10 de diciembre de 1987 [Repertorio de Jurisprudencia RJ 1987/9285]) ${ }^{26}$. Por tanto,

24 Ana María Casanovas-I-Mussons, Los sujetos de la aceptación: la capacidad y la legitimación para aceptar donaciones, en Homenaje al profesor Lluis Puig-i-Ferriol, tomo I, 795-822, 795796, Juan Manuel Abril-Campoy \& María Eulalia Amat-Llari, coords., Tirant lo Blanch, Valencia (2006).

25 Ana María Casanovas-I-Mussons, Los sujetos de la aceptación: la capacidad y la legitimación para aceptar donaciones, en Homenaje al profesor Lluis Puig-i-Ferriol, tomo I, 795-822, 796, Juan Manuel Abril-Campoy \& María Eulalia Amat-Llari, coords., Tirant lo Blanch, Valencia (2006). Advierte la autora que la capacidad para aceptar una donación por razón de matrimonio no viene determinada estrictamente por el criterio de la capacidad natural; el donatario del art. $1338 \mathrm{CC}$ es un menor cualificado por su capacidad matrimonial, que ciertamente presupone la capacidad natural pero que se determina por el criterio jurídico de la edad. Por ello, el art. 1338.2 CC resulta más restrictivo que la regla general a la que se remite (que solo requiere capacidad natural) porque parte de la capacidad jurídica especial para contraer matrimonio.

26 Pedro de Pablo-Contreras, Comentario al art. 624 CC, en Código Civil comentado, vol. II, 114, Ana Cañizares-Laso, Pedro de Pablo-Contreras, Francisco Javier Orduña-Moreno, Rosario Valpuesta-Fernández, dirs., Civitas-Thomson Reuters, Cizur Menor, Pamplona (2011). 
para ser donatario no se exige capacidad especial alguna (incluso el concebido puede recibir donaciones, aunque por medio de sus representantes, no él mismo al no tener la condición de persona física); la única capacidad exigida es la natural de entender y querer $^{27}$, siendo el único límite el que pueda establecer la ley ${ }^{28}$.

Solo carecerán de capacidad para aceptar donaciones las criaturas abortivas y las asociaciones o corporaciones no permitidas por la ley (analógicamente, art. $745 \mathrm{CC}$ ) 29 ; observamos que en estos casos no son personas, por lo que la conclusión es que toda persona que verdaderamente lo sea puede, en principio, recibir por donación, salvo que por excepción le esté prohibido para cierto caso $^{30}$. Y las donaciones a favor de personas inciertas serán nulas (analógicamente, art. $750 \mathrm{CC})^{31}$.

Si se trata de una persona jurídica, las donaciones serán aceptadas por sus representantes (art. 38 y $746 \mathrm{CC}$ ) ${ }^{32}$; pero si las repudian,

27 En este sentido, el art. 531.21.1 CCCat establece que "pueden aceptar donaciones las personas que tienen capacidad natural".

28 Como advierte Carlos Lasarte-Álvarez, Principios de derecho civil, Tomo III Contratos, Marcial Pons, Madrid, 199 (2012), el art. 625 CC al señalar que "podrán aceptar donaciones todos los que no estén especialmente incapacitados por ley para ello" puede resultar engañoso "al sugerir que el Derecho positivo está plagado de prohibiciones o incapacidades para ser donatario, aserto que no se corresponde con la realidad normativa, pues, en rigor (por aplicación analógica del art. 745 y salvando algunas prohibiciones específicas) solo las criaturas abortivas o las personas jurídicas no permitidas por la ley están inhabilitadas para ser donatarios".

29 José Castán-Tobeñas, Derecho Civil español, común y foral, Tomo IV, Derecho de obligaciones. Las particulares relaciones obligatorias, José FerRandis-VILELLA, revisión y puesta al día, Reus, Madrid, 235 (1993).

30 Manuel Albaladejo-García, Comentario al artículo 624 CC, en Comentarios al Código Civil y Compilaciones forales, tomo VIII, vol. 2, Artículos 618 a 656 del Código Civil, 121, ManueL Albaladejo, dir., Manuel Albaladejo-Garcia \& Silvia Diaz-Alabart, coment., Revista de Derecho Privado, Madrid (1986).

31 José María Manresa y Navarro, Comentarios al Código Civil español, V, 169, Pascual MarínPÉreZ, corrección, aumento y puesta al día, Reus, Madrid (1972).

32 La Sentencia del Tribunal Supremo STS 16 de febrero de 1993 [Repertorio de Jurisprudencia RJ 1993\1232] consideró valida la donación realizada a una Asociación de Antiguos alumnos de la Institución Libre de Enseñanza, a pesar de ser una asociación de dudosa personalidad ya que se habían destruido los archivos, aunque se la concedió por los folletos y boletines editados por la identidad. Además, se apoyó en el hecho de que el donante era titular del bien, tenía libre disposición del mismo y la formalizó en escritura pública aceptada por el donatario. Klaus Jochen Albiez-Dohrmann, Comentario a los artículos 625-628, en Comentarios al Código Civil, tomo IV, 4798, Rodrigo Bercovitz Rodríguez-Cano, dir., Tirant lo Blanch, Valencia (2013), se plantea si las personas jurídicas en fase de formación o constitución pueden ser donatarias, considerando que no debería haber especiales impedimentos para ello si existe la certeza de que se van a dar todos los pasos necesarios para su definitiva constitución. También se plantea si puede donarse a un ente inmaterial como las distintas advocaciones de la Virgen, en cuyo caso debe entenderse pertenecen a la Iglesia Católica. 
se necesitará la autorización judicial con audiencia del Ministerio público (art. $993 \mathrm{CC}$ en aplicación analógica).

Respecto al menor, hay que tener presente el art. 2.2 de la Ley 1/1996 o Ley Orgánica de Protección Jurídica del Menor, LOPJM ${ }^{33}$, que afirma que "las limitaciones a la capacidad de obrar de los menores se interpretará de forma restrictiva". El menor o el incapaz en relación con la propia sentencia, puede actuar eficazmente por sí mismo en todos los actos jurídicos puramente beneficiosos o no perjudiciales y en los de orden personalísimo y debe ser oído en la toma de decisiones que le afectan. El menor, o el incapacitado que pueda obrar por sí mismo a tenor de la sentencia, puede comparecer para aceptar por sí mismo y hacerlo en escritura pública si se trata de un bien inmueble (633.2 CC). El notario es quien apreciará la capacidad suficiente del menor (art. 167 del Régimen del Notariado, $\mathrm{RN}$ ). La capacidad del menor para aceptar donaciones puras y simples excluye toda intervención de sus representantes legales. A pesar de que el menor pueda aceptar una donación esto no impide que su representante legal pueda aceptar en nombre de su hijo ${ }^{34}$.

Si la persona carece de capacidad natural, se precisará de la aceptación por parte de los representantes legales y si estos no aceptan, será precisa la autorización judicial (art. 166 y 271.4 CC).

Respecto al declarado pródigo debería poder aceptar las donaciones con la precaución del curador para que no se despilfarre; y si hay un concurso de acreedores, el deudor podrá aceptarlas también, en cuyo caso los bienes no entran en la masa concursal en cuanto las donaciones sean posteriores a la declaración de concurso ${ }^{35}$.

La capacidad para aceptar la donación debe tenerse al momento de aceptarla y al de concluirse la donación ${ }^{36}$.

33 España, Ley 1/1996 o Ley Orgánica de Protección Jurídica del Menor, 15 Boletín Oficial del Estado, BOE, 17 de enero de 1996. Disponible en: https://www.boe.es/buscar/doc.php?id=BOEA-1996-1069

34 María Rosa Llácer-MatacÁs, Los presupuestos subjetivos de la aceptación de donaciones: las distintas acepciones de la capacidad, en Homenaje al profesor Lluis Puig-i-Ferriol, tomo II, 1673-1690, 1684, Juan Manuel Abril-Campoy \& María Eulalia Amat-Llari, coords., Tirant lo Blanch, Valencia (2006).

35 Klaus Jochen Albiez-Dohrmann, Comentario a los artículos 625-628, en Comentarios al Código Civil, tomo IV, 4800, Rodrigo Bercovitz Rodríguez-Cano, dir., Tirant lo Blanch, Valencia (2013).

36 Manuel Albaladejo-García \& Silvia Díaz-Alabart, La donación, 125, Centro de Estudios, Colegio de Registradores de la Propiedad, Mercantiles y de Bienes Muebles de España, Madrid (2006). 


\section{A. La aceptación de donaciones condicionales u onerosas: artículo $626 \mathrm{CC}, 1460$ y $1461 \mathrm{CCco}^{37}$}

El artículo $625 \mathrm{CC}$ regula una amplia capacidad para aceptar donaciones, a no ser que se esté "especialmente incapacitado por la ley para ello". Uno de estos supuestos en que la ley no permite aceptar donaciones está previsto en el artículo $626 \mathrm{CC}$ respecto a un tipo concreto de donaciones, para las que se exige una mayor capacidad, sin ser suficiente la simple capacidad natural. Advierte este precepto que "las personas que no pueden contratar no podrán aceptar donaciones condicionales u onerosas sin la intervención de sus legítimos representantes" ${ }^{38}$. Por tanto, del precepto deducimos que las donaciones condicionales u onerosas solo podrán aceptarse por personas con capacidad general de obrar, la necesaria para contratar, ya que conlleva un sacrificio por parte del donatario ${ }^{39}$. Si se trata de menores emancipados también podrán aceptar estas donaciones siempre que la carga no conlleve un acto de los mencionados en el art. $323 \mathrm{CC}$, en cambio, si se tratara de tales actos, se precisaría el asentimiento de los padres o curador. Si carecen de capacidad de obrar, serán los representantes legales los que deberán intervenir. En todo caso, implícitamente el $626 \mathrm{CC}$ nos advierte que las personas que no puedan contratar podrán aceptar donaciones no condicionales $\mathrm{u}$ onerosas sin la intervención de sus legítimos representantes ${ }^{40}$.

37 Art. 1460 CCco: "La donación a plazo o bajo condición no producirá efecto alguno, si no constare por escritura privada o pública en que se exprese la condición o plazo: y serán necesarias en ella la escritura pública en que se exprese la condición o plazo; y serán necesarias en ella la escritura pública y la insinuación e inscripción en los mismos términos que para las donaciones de presente"; art. 1461: "las donaciones con causa onerosa como que para una persona abrace una carrera o estado, o a título de dote, o por razón de matrimonio, se otorgarán por escritura pública, expresando las causas, y no siendo así, se considerarán como donaciones gratuitas".

$38 \mathrm{El}$ art. 531.21.2 CCCat, equivalente al art. $626 \mathrm{CC}$ advierte que "Las donaciones efectuadas con gravámenes, cargas o modos, a personas sometidas a potestad o a un régimen tutelar o de protección deben ser efectuadas con la intervención o asistencia de las personas que establece el libro segundo".

39 Ana María Casanovas-I-Mussons, Los sujetos de la aceptación: la capacidad y la legitimación para aceptar donaciones, en Homenaje al profesor Lluis Puig-i-Ferriol, tomo I, 795-822, 799800, Juan Manuel Abril-Campoy \& María Eulalia Amat-Llari, coords., Tirant lo Blanch, Valencia (2006).

40 Ídem, 799 y la argumentación de la autora a raíz de los antecedentes del art. 626 CC y su vinculación con el art. 1478 CC portugués de 1867. Portugal, Código Civil de 1867. Texto en portugués: http://purl.pt/12145 
No obstante, el precepto no es muy afortunado en el uso de los términos donaciones "condicionales" y "onerosas". Las donaciones sometidas a condición suspensiva o resolutoria no imponen carga alguna al donatario, por lo que sería suficiente la capacidad natural, al no haber una prestación del donatario que comprometa su patrimonio ${ }^{41}$.

La interpretación del artículo $626 \mathrm{CC}$ es que las donaciones condicionales y onerosas se entienden como sinónimos para designar aquellas donaciones en que se impone al donatario un gravamen inferior al valor de lo donado (art. $619 \mathrm{CC}$ ), respecto de las cuales los artículos 647 y 651.2 CC establecen el régimen jurídico del incumplimiento de ese gravamen o condiciones impuestas al donatario ${ }^{42}$. Este tipo de donaciones condicionales u onerosas a las que se refiere el artículo $626 \mathrm{CC}$ se reconducen a la noción de donación modal (obsérvense los arts. 647 y $651 \mathrm{CC}$ ). Ello es así, porque si la donación es modal es lógico que se exija una mayor capacidad al donatario, ya que, además de consentir la recepción de una atribución gratuita, asume una obligación coercible por medio de la revocación. En cambio, si consideramos que estamos ante una donación condicional, el donatario no se obliga a nada, ni aunque esa donación sea potestativa; lo único que sucede en este caso es que adquirirá o perderá el beneficio de modo automático si se incumple o se cumple la condición suspensiva o resolutoria ${ }^{43}$.

En estas donaciones condicionales u onerosas, como se apuntaba anteriormente, el art. 626 CC exige la capacidad de contratar y quien

41 Entre otros, Manuel Albaladejo-García, Comentario al artículo 626 CC, en Comentarios al Código Civil y Compilaciones forales, tomo VIII, vol. 2, Artículos 618 a 656 del Código Civil, 127, Manuel Albaladejo, dir., Manuel Albaladejo-García \& Silvia Díaz-Alabart, coment., Revista de Derecho Privado, Madrid (1986). María Rosa Llácer-Matacás, Los presupuestos subjetivos de la aceptación de donaciones: las distintas acepciones de la capacidad, en Homenaje al profesor Lluis Puig-i-Ferriol, tomo II, 1673-1690, 1685, JuAn Manuel Abril-CAMPoy \& MAría Eulalia Amat-Llari, coords., Tirant lo Blanch, Valencia (2006). Lucía Costas-Rodal, Contrato de donación, en Tratado de contratos, tomo II, 2167, n. 1536, Rodrigo Bercovitz Rodríguez-CANo, dir., Tirant lo Blanch, Valencia (2009), añade que "lo que ocurre en ese caso es que los efectos de la donación quedan pendientes de la condición, según sea suspensiva o resolutoria".

42 Ana María Casanovas-I-Mussons, Los sujetos de la aceptación: la capacidad y la legitimación para aceptar donaciones, en Homenaje al profesor Lluis Puig-i-Ferriol, tomo I, 795-822, 800 y 801, Juan Manuel Abril-Campoy \& María Eulalia Amat-Llari, coords., Tirant lo Blanch, Valencia (2006).

43 Miriam Anderson, Comentario al artículo 626 CC, en Código Civil comentado, vol. II, 115, Ana Cañizares-Laso, Pedro de Pablo-Contreras, Francisco Javier Orduña-Moreno, Rosario Valpuesta-Fernández, dirs., Civitas-Thomson Reuters, Cizur Menor, Pamplona (2011). 
no disponga de esta capacidad deberá contar con la intervención de su legítimo representante. El término intervención ha generado cierta discrepancia en su interpretación; es preciso concretar la intensidad de esta intervención y otorgar un significado u otro dependiendo del grado de incapacidad del donatario y del tipo de obligación que asuma.

Por una parte, se considera que "intervención" no supone sustitución de la persona del donatario, sino colaboración con este. Evidentemente, sí habrá sustitución en caso de inexistencia de capacidad natural, pero la intervención a la que se refiere el art. $626 \mathrm{CC}$ junto con la redacción del art. $631 \mathrm{CC}$, conlleva que el donatario menor o incapaz puede aceptar por sí mismo tanto las donaciones puras como las condicionales u onerosas, de forma que la aceptación de estas donaciones sería uno de los actos excluidos por disposición de ley de la representación legal a la que se refieren los arts. 162.1 y 267 CC. Por tanto, en estos casos, la actuación del representante sería un complemento de capacidad. En estos casos, el representante legal no actúa como tal (representativamente) sino en la función típica del actual curador (art. $288 \mathrm{CC}$ ): interviene en la declaración de voluntad ajena en una función complementadora de la capacidad de obrar insuficiente de su autor (porque solo tiene capacidad natural). Supone un plus de capacidad para aceptar donaciones con gravámenes al donatario que puede aceptar por sí mismo pero no puede hacerlo válidamente por sí solo ${ }^{44}$. Según

44 Ana María Casanovas-I-Mussons, Los sujetos de la aceptación: la capacidad y la legitimación para aceptar donaciones, en Homenaje al profesor Lluis Puig-i-Ferriol, tomo I, 795-822, 811812, Juan Manuel Abril-Campoy \& María Eulalia Amat-Llari, coords., Tirant lo Blanch, Valencia (2006). Manuel Albaladejo-García \& Silvia Díaz-Alabart, La donación, 153, La donación, Centro de Estudios, Colegio de Registradores de la Propiedad, Mercantiles y de Bienes Muebles de España, Madrid (2006). Klaus Jochen Albiez-Dohrmann, Comentario a los artículos 625-628, en Comentarios al Código Civil, tomo IV, 4804, Rodrigo BerCovitz Rodríguez-CAno, dir., Tirant lo Blanch, Valencia (2013). Miriam Anderson, Comentario al artículo 626 CC, en Código Civil comentado, vol. II, 116, Ana Cañizares-Laso, Pedro de Pablo-Contreras, Francisco Javier Orduña-Moreno, Rosario Valpuesta-Fernández, dirs., Civitas-Thomson Reuters, Cizur Menor, Pamplona (2011). Añade Miriam Anderson una interesante referencia a los derechos promulgados por las comunidades autonómicas. Así, en Aragón, la Ley 13/2006 o Ley de Derecho de la persona, de 27 de diciembre, afirma en el art. 11.2 que el representante legal del menor de 14 años precisará autorización previa de la Junta de parientes o del juez para aceptar donaciones modales u onerosas y si esta autorización se deniega, se entiende rechazada la donación. Aragón, Ley 13/2006 o Ley de Derecho de la persona, 23 Boletín Oficial del Estado, BOE, 26 de enero de 2007. Disponible en: mhttp://www. boe.es/boe/dias/2007/01/26/pdfs/A03713-03739.pdf

En un sentido similar se expresa el art. 236.27.1.e CCCat, que exige que los titulares de la potestad parental cuenten con la autorización judicial para aceptar donaciones modales 
esta postura, si los representantes legales no han intervenido, la donación sería anulable.

Por otro lado, otro sector de la doctrina considera que dado que se está ante un donatario sin capacidad para contratar, parece incoherente esa significación de la intervención, y más aceptable la de sustitución. Es decir, si el donatario no tiene capacidad natural, actuará su representante; y si dispone de tal capacidad, será necesaria la sustitución en la prestación del consentimiento para contraer la concreta obligación de que se trate siempre según las normas generales aplicables en materia de contratos ${ }^{45}$. En este caso, la falta de intervención de los representantes supondría la nulidad plena de la adopción.

En cuanto a los menores, la Ley 1/1996, LOPJM, por medio de su disposición final DF 18 eliminó la necesidad de autorización judicial para que los progenitores pudieran repudiar donaciones en el ámbito del CC (art. 166 CC) $)^{46}$, pero nada advirtió sobre la tutela,

u onerosas, lo que debe ponerse en relación con el art. 531.21.2 CCCat, según el cual las donaciones hechas con gravámenes, cargas o modos a personas sujetas a potestad parental, tutela u otro régimen de protección deben ser aceptadas con la intervención o asistencia de las personas que establece el libro segundo. Lo mismo se establece respecto a los tutores [art. 222.42.1.e)]. Cataluña, Código Civil de Cataluña. Disponible en: http://civil.udg.es/normacivil/ cat/ccc/ES/Index.htm

Pero en la legislación catalana surge un problema: la Ley 1/1996 o Ley de Protección Jurídica del Menor a través de su disposición final DF 18 eliminó la necesidad de autorización judicial para que los progenitores pudieran repudiar donaciones en el ámbito del CC (art. 166 CC), pero nada advirtió respecto la tutela (art. 271.4 CC). España, Ley 1/1996 o Ley Orgánica de Protección Jurídica del Menor, 15 Boletín Oficial del Estado, BOE, 17 de enero de 1996. Disponible en: https://www.boe.es/buscar/doc.php?id=BOE-A-1996-1069

La ley catalana, en cambio, exige dicha autorización judicial para repudiar donaciones tanto a los padres como tutores (arts. 236.27.1.e CCCat y 222.43.1 CCCat). Si se deniega la autorización, se entiende que conlleva la aceptación de la transmisión, y sería más coherente que en el caso de denegación de autorización implicara la repudiación, como establece el art. 11 Ley 13/2006 Ley aragonesa. Este artículo 11.1 afirma que si no se obtiene autorización para repudiar la donación, se entiende automáticamente aceptada, pero en el art. 11.2 prevé la solución contraria si se deniega la autorización para aceptar una donación modal u onerosa.

45 Luis Díez-Picazo y Ponce de León \& Antonio Gullón-Ballesteros, Sistema de Derecho civil, vol. 2, tomo 2, Tecnos, Madrid, 78 (2012), a pesar de afirmar que intervención no implica sustitución de la persona del donatario, sino colaboración con este, acaban afirmando que "al tratarse de un donatario que no tiene capacidad para contratar, parece incoherente esa significación de la intervención, y más aceptable el de sustitución”. FrANCISCO MARÍN-CASTÁN, Comentario al artículo 626 CC, en Comentario del Código Civil, tomo IV, 111, Ignacio SierraGil de la Cuesta, coord., Bosch, Barcelona (2000).

46 María Rosa Llácer-MatacÁs, Los presupuestos subjetivos de la aceptación de donaciones: las distintas acepciones de la capacidad, en Homenaje al profesor Lluis Puig-i-Ferriol, tomo II, 1673-1690, 1686, Juan Manuel Abril-Campoy \& María Eulalia Amat-Llari, coords., Tirant lo Blanch, Valencia (2006), considera que la autorización es superflua si pensamos que la carga no es exigible en lo que sobrepase el valor de lo donado (arts. 619 y 642 Cc). "La afección que representa la carga unida al mencionado límite económico explica que, por un lado, se eleve 
por lo que necesitan autorización para repudiar la donación (art. $271.4 \mathrm{Cc}$ ). De los arts. 166 y $162.1 \mathrm{Cc}$ (referente este último a la exclusión de la representación paterna de los actos que los hijos, con sus condiciones de madurez, puedan realizar por sí mismos), puede deducirse que el menor maduro puede aceptar por sí la donación, de lo contrario lo harán sus padres como representantes, sin perjuicio de la intervención de un defensor judicial si existe conflicto de intereses entre los menores o incapacitados y sus representantes legales o curador (art. 299.1 Cc). Si un menor o incapaz acepta las donaciones condicionales u onerosas sin la intervención de sus representantes supondrá una nulidad o anulabilidad del acto.

Si se trata de una fundación la aceptación de una donación onerosa o remuneratoria o su repudiación se comunicará por parte del patronato al protectorado para que lo valoren y pueda ejercer el Protectorado las acciones de responsabilidad contra los patronos si los actos de los mismos son lesivos para la fundación (art. 22.2 LF) ${ }^{47}$.

\section{B. Las donaciones hechas a personas inhábiles: artículo 628 CC y art. 1449 CCco}

Para disuadir posibles fraudes, como evitar que una persona especialmente incapacitada por ley para ello reciba una donación o para evitar que se acepten aquellas donaciones realizadas para fomentar o retribuir la toma de decisiones o resoluciones injustas constitutivas de delito (art. $625 \mathrm{CC}$ ), el artículo $628 \mathrm{CC}$ declara la nulidad de tales donaciones, aunque lo hayan sido simuladamente bajo la apariencia de otro contrato o por persona interpuesta (testaferro). El artículo $628 \mathrm{CC}$ establece: "las donaciones hechas a personas

\footnotetext{
el requisito de capacidad mientras que, por otro, no sea necesaria la autorización. Aun así deberá solicitarse si la carga conlleva un acto necesitado de autorización y el juez valorará su entidad en el contexto de la adquisición y su repercusión general en los intereses del representado".

47 Con la anterior Ley de Fundaciones, LF, la Ley 20/1994, para aceptar o repudiar donaciones onerosas o remuneratorias se necesitaba la autorización previa del Protectorado (los arts. 11.4 y 11.5 y art. 10.2 del Real Decreto 316/1996 permitía subsanar la repudiación o aceptación de las donaciones con carga autorizando a posteriori). España, Ley 20/1994 o Ley de reforma del artículo 54 de la Ley de Registro Civil, 161 Boletín Oficial del Estado, BOE, 7 de julio de 1994. Disponible en: https://www.boe.es/diario_boe/txt.php?id=BOE-A-1994-15795. España, Real Decreto 316/1996, de 23 de febrero, por el que se aprueba el Reglamento de Fundaciones de Competencia Estatal, 57 Boletín Oficial del Estado, BOE, 6 de marzo de 1996. Disponible en: https://www.boe.es/boe/dias/1996/03/06/pdfs/A08848-08859.pdf
} 
inhábiles son nulas, aunque lo hayan sido simuladamente, bajo la apariencia de otro contrato por persona interpuesta". El precepto no dice "las donaciones aceptadas por personas inhábiles", sino "las donaciones hechas"

Por personas inhábiles se entiende aquellas personas a quienes no puede hacerse donación; aquellas a quienes la ley prohíbe recibir en concepto de donatarios, a pesar de que estas personas en circunstancias normales no tienen restricción alguna de capacidad. Es el caso, por ejemplo, de la prohibición a quienes desempeñen un cargo tutelar de recibir donaciones del tutelado o de sus causahabientes, mientras no haya sido aprobada definitivamente su gestión (art. 221.1 CC o 1449 CCco) ${ }^{49}$. La Sentencia del Tribunal Supremo STS 1180/1997, 23 de diciembre Repertorio de Jurisprudencia RJ 1997\8902, extiende esta prohibición a todo cargo tutelar, por ejemplo al curador ${ }^{50}$.

Tampoco podrían recibir donaciones quienes ejercen funciones o potestades públicas. Es el caso de los notarios, los cuales no pueden autorizar actos que contengan disposiciones a su favor, o en los que intervengan como representantes de terceros. La inhabilidad alcanza a los parientes del notario hasta el cuarto grado de consanguinidad o segundo de afinidad y al cónyuge (art. 22, 27 y 28 LN y 139 Rnot) ${ }^{51}$. Se trata de donaciones recibidas para fomentar o retribuir la toma de decisiones o el dictado de resoluciones injustas eventualmente constitutivas de delito (prevaricación). Serían donaciones nulas con la necesidad de restituir lo donado ${ }^{52}$.

48 José María Manresa y Navarro, Comentarios al Código Civil español, V, 175-177, Pascual Marín-PÉrez, corrección, aumento y puesta al día, Reus, Madrid (1972).

49 En la redacción originaria del CC había más limitaciones, por ejemplo, las donaciones entre cónyuges constante matrimonio (antiguo art. $1334 \mathrm{CC}$ ), las hechas durante el matrimonio por uno de ellos a los hijos habidos por el otro en distinto matrimonio o a las personas de las que sea heredero presunto al tiempo de la donación (antiguo art. 1335 CC). Estas limitaciones han quedado suprimidas a raíz del art. 1323 CC.

50 En el mismo sentido, Klaus Jochen Albiez-Dohrmann, Comentario a los artículos 625-628, en Comentarios al Código Civil, tomo IV, 4806, Rodrigo Bercovitz Rodríguez-Cano, dir., Tirant lo Blanch, Valencia (2013).

51 España, Ley de 28 de mayo de 1862 o Ley Orgánica del Notariado, 80 Gaceta de Madrid, 29 de mayo de 1862. Disponible en: https://www.boe.es/datos/pdfs/BOE/1862/149/A00001-00001. pdf. España, Decreto de 2 de junio de 1944, por el que se aprueba con carácter definitivo el Reglamento de la organización y régimen del Notariado, 189 Boletín Oficial del Estado, BOE, 7 de julio de 1944. Texto actualizado disponible en: https://www.boe.es/buscar/act.php?id=BOEA-1944-6578

52 Pedro de Pablo-Contreras, Comentario al art. 624 CC, en Código Civil comentado, vol. II, 144, Ana Cañizares-Laso, Pedro de Pablo-Contreras, Francisco Javier Orduña-Moreno, 
Surge la duda de si la prohibición afecta también a los sacerdotes que confiesan al donante durante su última enfermedad, a sus parientes hasta el cuarto grado, a su iglesia, cabildo, comunidad o instituto (art. $752 \mathrm{Cc}$ ). El artículo $4.2 \mathrm{CC}$ es contrario a la interpretación extensiva de las normas prohibitivas, lo que sucede es que el supuesto de hecho es el mismo que en el caso de los notarios: captación de la voluntad en las liberalidades inter vivos y mortis $\operatorname{causa}^{53}$, por lo que puede defenderse su inhabilidad.

La sanción de la prohibición es la nulidad absoluta del acto, "aunque lo haya sido simuladamente, bajo apariencia de otro contrato, por persona interpuesta" (art. 6.3 CC, añadiendo la posibilidad de asistir, además, ante un fraude de ley, art. $6.4 \mathrm{CC}$ ). El precepto adolece de una imprecisión ya que debería decir "simuladamente bajo apariencia de otro contrato, o por persona interpuesta". Es decir, se contemplan dos supuestos: el caso que se simule que el contrato que se otorga no es donación, o el caso que se simule que es donación a favor de otro donatario, no del real ${ }^{54}$.

El artículo $628 \mathrm{CC}$ está muy vinculado con los supuestos de simulación de un contrato de compraventa de un inmueble mediante escritura pública, cuando en realidad se trata de encubrir una donación. De este modo se evita el supuesto de hecho del artículo $628 \mathrm{CC}$, se obtienen con ello beneficios fiscales, se defrauda a los legitimarios, disminuyen los bienes de donante a efectos de no permitir cobrar las deudas a sus acreedores, etc. La duda es si el

Rosario Valpuesta-Fernández, dirs., Civitas-Thomson Reuters, Cizur Menor, Pamplona (2011).

53 Daniel Ferrer-Martín, La incapacidad relativa para suceder del artículo 752 del Código civil, Revista de Derecho Privado, Madrid, 1004 (1951), defiende una interpretación restrictiva. Manuel González-Meneses García Valdecasas, La donación, en Instituciones de Derecho Privado, tomo III, vol. 2, 683, Juan Francisco Delgado de Miguel, coord., Consejo General del Notariado y Thomson Civitas, Madrid (2004), en contra de Manuel Albaladejo-García, Comentario al artículo 625 CC, en Comentarios al Código Civil y Compilaciones forales, tomo VIII, vol. 2, Artículos 618 a 656 del Código Civil, 126, Manuel Albaladejo, dir., Manuel Albaladejo-García \& Silvia Díaz-Alabart, coment., Revista de Derecho Privado, Madrid (1986), que defiende que la prohibición del artículo 752 CC es aplicable también a las donaciones.

54 Manuel Albaladejo-García, Comentario al artículo 628 CC, en Comentarios al Código Civil y Compilaciones forales, tomo VIII, vol. 2, Artículos 618 a 656 del Código Civil, 138-139, MANuEL Albaladejo, dir., Manuel Albaladejo-García \& Silvia Díaz-Alabart, coment., Revista de Derecho Privado, Madrid (1986). Manuel Albaladejo-García \& Silvia Díaz-Alabart, La donación, 164, Centro de Estudios, Colegio de Registradores de la Propiedad, Mercantiles y de Bienes Muebles de España, Madrid (2006). Klaus Jochen Albiez-Dohrmann, Comentario a los artículos 625-628, en Comentarios al Código Civil, tomo IV, 4807, Rodrigo Bercovitz Rodríguez-CANo, dir., Tirant lo Blanch, Valencia (2013). 
contrato disimulado, la donación, debe o no considerarse válido. La jurisprudencia es dispar:

- En algunas ocasiones se decanta por la validez de la donación disimulada en virtud del artículo $1276 \mathrm{CC}$, a no ser que sea nulo por ilicitud de la causa (art. 1275 CC). Por ejemplo, si se hace para perjudicar la legítima de los herederos forzosos o los acreedores (Sentencia del Tribunal Supremo STS 397/1995, 5 de mayo Repertorio de Jurisprudencia RJ 1995\3897), o para vulnerar una prohibición de disponer legal o testamentaria (STS 10 de marzo de 1978 Repertorio de Jurisprudencia RJ 19781811). La validez de la donación se defiende especialmente en caso de donaciones remuneratorias por la remisión del artículo $622 \mathrm{CC}$ a las reglas de los contratos cuando el servicio que se remunera vale igual o más que lo donado (Sentencia del Tribunal Supremo STS 222/1995, 14 marzo Repertorio de Jurisprudencia RJ 1995\2430). Pero esto no evita la nulidad de pleno derecho de la donación disimulada que proclama el art. $628 \mathrm{CC}$ en los casos allí previstos.

- En otras ocasiones, considera que las donaciones de inmuebles disimuladas con una compraventa son siempre nulas por no cumplir los requisitos de forma de solemnidad previstos en el artículo 633 CC: no constar en la escritura el ánimo de donar y la voluntad de aceptar. Es el caso de las SSTS 1394/2007, 11 de enero Repertorio de Jurisprudencia RJ 2007\1502; 204/2007, 26 de febrero Repertorio de Jurisprudencia RJ 2007\1769; 956/2007, 10 de septiembre Repertorio de Jurisprudencia RJ 2007\4980; 236/2008, 18 de marzo Repertorio de Jurisprudencia RJ 200813054; 317/2008, 5 de mayo Repertorio de Jurisprudencia RJ 200814130; 287/2009, 4 de mayo Repertorio de Jurisprudencia RJ 2009\2905; 378/2009, 27 de mayo Repertorio de Jurisprudencia RJ 2009।3045; 826/2009, 21 de diciembre Repertorio de Jurisprudencia RJ 2010\297; 25/2010, 3 de febrero Repertorio de Jurisprudencia RJ 2010\4215.

55 Pedro de Pablo-Contreras, Comentario al art. 624 CC, en Código Civil comentado, vol. II, 120, Ana Cañizares-Laso, Pedro de Pablo-Contreras, Francisco Javier Orduña-Moreno, Rosario Valpuesta-Fernández, dirs., Civitas-Thomson Reuters, Cizur Menor, Pamplona (2011), se decanta por esta tesis pues no se puede atribuir a lo simulado como compraventa el efecto transmisivo propio de la donación. 


\section{Las donaciones a los concebidos no nacidos}

Los concebidos no nacidos pueden recibir donaciones, pero serán aceptadas por las personas que legítimamente los representarían si se hubiera verificado su nacimiento (art. $627 \mathrm{CC}$ ), debiendo notificarlo al donante ${ }^{56}$. Este precepto es congruente con el artículo 29 CC, según el cual "el concebido se tiene por nacido para todos los efectos que le sean favorables". También observamos la protección al nascitūrus en el art. 93 CCco: "Los derechos que se diferirían a la criatura que está en el vientre materno, si hubiese nacido y viviese, estarán suspensos hasta que el nacimiento se efectúe. Y si el nacimiento constituye un principio de existencia, entrará el recién nacido en el goce de dichos derechos, como si hubiese existido al tiempo en que se defirieron. En el caso del inciso del artículo 90 pasarán estos derechos a otras personas, como si la criatura no hubiese jamás existido".

Esto no supone conceder personalidad jurídica al concebido, sino que es una facultad excepcional que se otorga para proteger sus derechos, dado que estamos en presencia de un efecto favorable para él y se pretende perfeccionar la donación a fin de que el donante quede desde ese momento vinculado. Por ello, el Código permite aceptar provisionalmente la donación por parte de quien sería su representante, si hubiera nacido (una especie de quasi representación), convirtiendo de este modo en irrevocable la donación durante ese período de gestación ${ }^{57}$. Estos representantes serán habitualmente los padres o, por lo menos, la madre podrá aceptar, dado que al ser un período de gestación la madre siempre existirá y se sabrá quién es. Si la madre es menor y soltera y goza de capacidad natural, según el art. 625 CC podría aceptar por sí sola la donación a favor de su hijo concebido sin ser necesaria la intervención de sus padres o tutores $(157 \mathrm{CC})$. El problema puede generarse si el padre es desconocido y la madre incapacitada (que en todo caso no podría ser la representante del gestante al nacer). En estos supuestos, debería nombrarse un defensor judicial que es

56 El artículo 531-21.3 CCCat: "Las personas que serían los representantes legales de los concebidos si ya hubiesen nacido pueden aceptar las donaciones que se efectúen a favor de estos".

57 Esther Arroyo-i-Amayuela, La protección al concebido en el Código Civil, Cuadernos Civitas, Madrid, 137 (1992). 
quien aceptaría la donación o que fuera el Ministerio fiscal el que procediera a tal aceptación dado que es el que debe defender a un menor que debe someterse a tutela mientras no es nombrado este último judicialmente (art. 222 bis CC) ${ }^{58}$.

Ahora bien, es desde el momento en que se conoce la aceptación por parte del donante cuando la donación obliga y produce efectos (arts. 623, 629, 631 y $633 \mathrm{CC}$ ). Hasta cuando el nacimiento tenga lugar, el donante conservará los bienes, sin poder revocarla ni disponer de ellos, aunque falleciera el donante tras la aceptación. Esta aceptación por parte del representante no puede provocar la eficacia real transmisiva de la donación, sino hasta el nacimiento del concebido en las condiciones legales: en el momento de la aceptación no hay adquirente, porque sin personalidad no hay capacidad para adquirir (art. 745.1 CC). La ficción legal del art. 29 no excepciona el art. $745.1 \mathrm{CC}$, porque no pretende crear derechos sin sujetos. Su finalidad, en relación con el artículo $627 \mathrm{CC}$ es propiciar la aceptación anticipada de la donación para evitar su desaparición, para independizar la subsistencia del negocio de la vida o la voluntad del donante ${ }^{59}$.

En todo caso, esto será posible, siempre que se cumpla una condición: nacer con los requisitos del artículo $30 \mathrm{CC}$ : haber nacido

58 Manuel Albaladejo-García, Comentario al artículo 627 CC, en Comentarios al Código Civil y Compilaciones forales, tomo VIII, vol. 2, Artículos 618 a 656 del Código Civil, 1596, MANUEL Albaladejo, dir., Manuel Albaladejo-García \& Silvia Díaz-Alabart, coment., Revista de Derecho Privado, Madrid (1986). Carlos Martínez de Aguirre y Aldaz, Comentario al art. 627, en Código Civil comentado, vol. II, 118, Ana Cañizares-Laso, Pedro de Pablo-Contreras, Francisco Javier Orduña-Moreno, Rosario Valpuesta-Fernández, dirs., Civitas-Thomson Reuters, Cizur Menor, Pamplona (2011). Miriam Anderson, Comentario al artículo 626 CC, en Código Civil comentado, vol. II, 118, Ana Cañizares-Laso, Pedro de Pablo-Contreras, Francisco Javier Orduña-Moreno, Rosario Valpuesta-Fernández, dirs., Civitas-Thomson Reuters, Cizur Menor, Pamplona (2011).

59 Ana María Casanovas-I-Mussons, Los sujetos de la aceptación: la capacidad y la legitimación para aceptar donaciones, en Homenaje al profesor Lluis Puig-i-Ferriol, tomo I, 795-822, 821, JUAN Manuel Abril-Campoy \& María Eulalia Amat-Llari, coords., Tirant lo Blanch, Valencia (2006). La autora matiza la diferencia entre el art. 627 CC y el supuesto en que el nascitūrus es nombrado heredero (art. 759 ss CC). En estos casos, la herencia se pone en administración (arts. 965 y 967) y quedan en suspenso las operaciones particionales (art. 966 CC), mientras se espera que el nacimiento o su frustración resuelvan la incertidumbre sobre quién y cuántos son los herederos efectivamente delados. La aceptación inmediata de la herencia en nombre del concebido no es posible. Opina la autora que "permitir una aceptación avanzada no tendría ninguna utilidad: el causante ya ha perdido la titularidad de sus bienes y el testamento — si lo hay - ha adquirido valor negocial irrevocable por el hecho de la muerte. A diferencia de la aceptación de la donación (arts. 633.2, 623 y 627), la de la herencia (art. 988 ss) es una declaración de voluntad recepticia que se refiere únicamente al título sucesorio y cuya eficacia es, precisamente por ello, exclusivamente adquisitiva". 
con vida y haberse producido el entero desprendimiento del seno materno. Mientras tanto, el representante no puede pedir la entrega del bien objeto de donación y hasta el nacimiento los bienes donados quedan en situación de pendencia como si se tratara de bienes reservados. Si el donante entrega voluntariamente los bienes donados antes del nacimiento y este no llega a producirse, deberán restituirse con los frutos y rentas generadas desde el momento de la entrega. Una vez que se produce el nacimiento en las condiciones establecidas en el artículo $30 \mathrm{CC}$, la titularidad se consolida con eficacia desde la aceptación por parte de los representantes.

Los no concebidos no se benefician del artículo $627 \mathrm{CC}^{60}$. Sin embargo, en el ordenamiento hay mecanismos que permiten realizar atribuciones a favor los no concebidos de forma indirecta o condicional. Existe la posibilidad de realizar una donación con cláusula de reversión, es decir, el donante puede establecer que los bienes donados a favor de una determinada persona acaben revirtiendo a favor de otro a partir de una fecha o hecho que se establezca como condición. $\mathrm{O}$ acudir a la sustitución fideicomisaria en Derecho de sucesiones ${ }^{61}$. En el Código Civil de Cataluña se ha admitido la posibilidad de hacer una donación a favor del nondum concepti pero sometida a condición suspensiva, en cuyo caso no hay intermediarios y la donación es a favor de la persona que aún no ha sido concebida, aunque los efectos de la donación no se verificarán hasta cuando tenga lugar el nacimiento ${ }^{62}$.

60 Manuel Albaladejo-García, Comentario al artículo 627 CC, en Comentarios al Código Civil y Compilaciones forales, tomo VIII, vol. 2, Artículos 618 a 656 del Código Civil, 1596, MANUEL Albaladejo, dir., Manuel Albaladejo-García \& Silvia Díaz-Alabart, coment., Revista de Derecho Privado, Madrid (1986), considera que no (Ídem Comentario al art. 627 Cc en Comentarios al Código Civil..., ob. cit., p. 133). Manuel Albaladejo-García \& Silvia Díaz-Alabart, La donación, 158, La donación, Centro de Estudios, Colegio de Registradores de la Propiedad, Mercantiles y de Bienes Muebles de España, Madrid (2006). Esther Arroyo-I-Amayuela, La protección al concebido en el Código Civil, Cuadernos Civitas, Madrid, 137 (1992). José LuIS Díez-PAstor, La donación al no concebido, VI Anales de la Academia Matritense del Notariado, $A A M N, 146$ (1952), lo defiende siendo los padres los que aceptan una donación directa a favor de hijos futuros. Pero cabe recordar el art. $750 \mathrm{CC}$ y la nulidad de la donación a favor de personas inciertas.

61 Lucía Costas-Rodal, Contrato de donación, en Tratado de contratos, tomo II, 2168, n. 1538, Rodrigo Bercovitz Rodríguez-Cano, dir., Tirant lo Blanch, Valencia (2009).

62 En este sentido, el artículo 531.21.4 CCCat afirma que "las donaciones efectuadas a favor de los no concebidos se entienden hechas bajo condición suspensiva". Como afirma KLAus Jochen Albiez-Dohrmann, Comentario a los artículos 625-628, en Comentarios al Código Civil, tomo IV, 4797, Rodrigo Bercovitz Rodríguez-Cano, dir., Tirant lo Blanch, Valencia (2013), "esto significa que el bien donado queda en manos del donante, quien, no obstante, no puede disponer del mismo hasta que se cumpla la condición, debiendo, por tanto, conservarlo 
Respecto a las donaciones que puedan realizarse a embriones concebidos in vitro antes de la implantación al útero materno, a raíz de los artículos 8 y 9 de la Ley 14/2006, de 26 de mayo, sobre Técnicas de Reproducción Asistida (LTRA) ${ }^{63}$, podrían aceptar los que serían legalmente sus padres: la madre usuaria de la técnica a quien se le implantará el embrión, su marido o quien consintió la fecundación de la mujer (pareja de hecho o pareja del mismo sexo). En ningún caso, el donante anónimo de gametos (art. 8.3 LTRA) ${ }^{64}$.

adecuadamente. Para evitar este tipo de situaciones, el que quiera donar no obstante a un conceptūrus puede fijar un límite temporal para el cumplimiento de la condición suspensiva".

63 España, Ley 14/2006 o Ley sobre técnicas de reproducción humana asistida, LTRA, 126 Boletín Oficial del Estado, BOE, 27 de mayo de 2006. Disponible en: https://www.boe.es/buscar/act. php?id=BOE-A-2006-9292

64 Klaus Jochen Albiez-Dohrmann, Comentario a los articulos 625-628, en Comentarios al Código Civil, tomo IV, 4798, Rodrigo Bercovitz Rodríguez-Cano, dir., Tirant lo Blanch, Valencia (2013). Carlos Martínez de Aguirre y Aldaz, Comentario al art. 627, en Código Civil comentado, vol. II, 118, Ana Cañizares-Laso, Pedro de Pablo-Contreras, Francisco Javier Orduña-Moreno, Rosario Valpuesta-Fernández, dirs., Civitas-Thomson Reuters, Cizur Menor, Pamplona (2011). 


\section{BIBLIOGRAFÍA}

\section{Libros}

Albaladejo-García, Manuel, Comentario al art. 624 CC, en Comentario del Código Civil, tomo I, Ministerio de Justicia, Madrid (1993).

Albaladejo-García, Manuel \& Díaz-Alabart, Silvia, La donación, Centro de Estudios, Colegio de Registradores de la Propiedad, Mercantiles y de Bienes Muebles de España, Madrid (2006).

Arroyo-i-Amayuela, Esther, La protección al concebido en el Código Civil, Cuadernos Civitas, Madrid (1992).

Castán-Tobeñas, José, Derecho Civil español, común y foral, Tomo IV, Derecho de obligaciones. Las particulares relaciones obligatorias, José FERRANDIS-VILELLA, revisión y puesta al día, Reus, Madrid (1993).

Díez-Picazo y Ponce de León, Luis \& Gullón-Ballesteros, Antonio, Sistema de Derecho civil, vol. 2, tomo 2, Tecnos, Madrid (2012).

Lasarte-Álvarez, Carlos, Principios de derecho civil, Tomo III Contratos, Marcial Pons, Madrid (2012).

Lete del Río, José Manuel \& Lete-Achirica, Javier, Derecho de obligaciones, vol. II, Aranzadi, Cizur Menor, Navarra (2006).

Manresa y Navarro, José María, Comentarios al Código Civil español, V, 7 ed., Pascual MARín-PÉrez, corrección, aumento y puesta al día, Reus, Madrid (1972).

Puig-Ferriol, Luis, Comentario al artículo 323 CC, en Comentario del Código Civil, 2 ed., Ministerio de Justicia, Madrid (1993).

Vaquer-Aloy, Antonio, La donación en España y en Europa, Reus, Madrid (2012).

\section{Contribuciones en obras colectivas}

Albaladejo-García, Manuel, Comentario al artículo 624 CC, en Comentarios al Código Civil y Compilaciones forales, tomo VIII, vol. 2, Artículos 618 a 656 del Código Civil, Manuel Albaladejo, dir., Manuel Albaladejo-García \& Silvia DíazAlabart, coment., Revista de Derecho Privado, Madrid (1986).

Albaladejo-García, Manuel, Comentario al artículo 625 CC, en Comentarios al Código Civil y Compilaciones forales, tomo VIII, vol. 2, Artículos 618 a 656 del Código Civil, Manuel Albaladejo, dir., Manuel Albaladejo-García \& Silvia DíazAlabart, coment., Revista de Derecho Privado, Madrid (1986).

Albaladejo-García, Manuel, Comentario al artículo 626 CC, en Comentarios al Código Civil y Compilaciones forales, tomo VIII, vol. 2, Artículos 618 a 656 del Código Civil, Manuel Albaladejo, dir., Manuel Albaladejo-García \& Silvia DíazAlabart, coment., Revista de Derecho Privado, Madrid (1986).

Albaladejo-García, Manuel, Comentario al artículo 627 CC, en Comentarios al Código Civil y Compilaciones forales, tomo VIII, vol. 2, Artículos 618 a 656 del Código 
Civil, Manuel Albaladejo, dir., Manuel Albaladejo-García \& Silvia DíazAlabart, coment., Revista de Derecho Privado, Madrid (1986).

Albaladejo-García, Manuel, Comentario al artículo 628 CC, en Comentarios al Código Civil y Compilaciones forales, tomo VIII, vol. 2, Artículos 618 a 656 del Código Civil, Manuel Albaladejo, dir., Manuel Albaladejo-García \& Silvia DíazAlabart, coment., Revista de Derecho Privado, Madrid (1986).

Albiez-Dorhmann, Klaus Jochen, Comentario al artículo 624 CC, en Comentarios al Código Civil, tomo IV, Rodrigo Bercovitz Rodríguez-Cano, dir., Tirant lo Blanch, Valencia (2013).

Albiez-Dorhmann, Klaus Jochen, Comentario a los artículos 625-628, en Comentarios al Código Civil, tomo IV, Rodrigo Bercovitz Rodríguez-Cano, dir., Tirant lo Blanch, Valencia (2013).

Anderson, Miriam, Comentario al artículo 626 CC, en Código Civil comentado, vol. II, Ana Cañizares-Laso, Pedro de Pablo-Contreras, Francisco Javier OrduñaMoreno, Rosario Valpuesta-Fernández, dirs., Civitas-Thomson Reuters, Cizur Menor, Pamplona (2011).

Casanovas-i-Mussons, Ana María, De las personas que pueden hacer donaciones: la capacidad de obrar y el poder de disposición del donante, en Libro homenaje al profesor Manuel Albaladejo-García, tomo I, 857-876, José Manuel GonzÁlezPorras \& Fernando Pedro Méndez-González, Universidad de Murcia, Colegio de Registradores de la Propiedad, Mercantiles y de Bienes Muebles de España, Murcia, Madrid (2004).

Casanovas-I-Mussons, Ana María, Los sujetos de la aceptación: la capacidad y la legitimación para aceptar donaciones, en Homenaje al profesor Lluis Puig-i-Ferriol, tomo I, 795-822, Juan Manuel Abril-Campoy \& María Eulalia Amat-Llari, coords., Tirant lo Blanch, Valencia (2006).

Costas-Rodal, Lucía, Contrato de donación, en Tratado de contratos, tomo II, Rodrigo Bercovitz Rodríguez-Cano, dir., Tirant lo Blanch, Valencia (2009).

González-Meneses García Valdecasas, Manuel, La donación, en Instituciones de Derecho Privado, tomo III, vol. 2, Juan Francisco Delgado de Miguel, coord., Consejo General del Notariado y Thomson Civitas, Madrid (2004).

González-Pacanowska, Isabel, Apoderamiento y donación (Mandato general de donar cui voles e quid voles), en Estudios Jurídicos en Homenaje a Vicente L. MontésPenadés, 1273-1289, Francisco de Paula Blasco-Gascó, coord., Tirant lo Blanch, Valencia (2011).

Llácer-MatacÁs, María Rosa, Los presupuestos subjetivos de la aceptación de donaciones: las distintas acepciones de la capacidad, en Homenaje al profesor Lluis Puig-iFerriol, tomo II, 1673-1690, Juan Manuel Abril-Campoy \& María Eulalia Amat-Llari, coords., Tirant lo Blanch, Valencia (2006).

Marín-Castán, Francisco, Comentario al artículo 626 CC, en Comentario del Código Civil, tomo IV, Ignacio Sierra-Gil de la Cuesta, coord., Bosch, Barcelona (2000).

Martínez de Aguirre y Aldaz, Carlos, Comentario al art. 627, en Código Civil comentado, vol. II, Ana Cañizares-Laso, Pedro de Pablo-Contreras, Francisco Javier Orduña-Moreno, Rosario Valpuesta-Fernández, dirs., Civitas-Thomson Reuters, Cizur Menor, Pamplona (2011). 
Nieto-Alonso, Antonia, Comentario a los artículos 624 a 629 CC, en Comentarios al Código Civil, Andrés Domínguez-Luelmo, dir., Lex Nova, Valladolid (2010).

Pablo-Contreras, Pedro de, Comentario al art. 624 CC, en Código Civil comentado, vol. II, Ana Cañizares-Laso, Pedro de Pablo-Contreras, Francisco Javier OrduñaMoreno, Rosario Valpuesta-Fernández, dirs., Civitas-Thomson Reuters, Cizur Menor, Pamplona (2011).

Rivero-Hernández, Francisco, Elementos de Derecho civil II, Derecho de obligaciones, vol. II, Contratos y cuasicontratos. Delito y cuasidelito, José Luis LACRuz-BerdeJo, Francisco de Asís Sancho-Rebullida, Agustín Luna-Serrano \& Francisco Rivero-Hernández, Dykinson, Madrid (2009).

Vaquer-Aloy, Antonio, Derecho europeo de contratos, libro II y IV del Marco Común de Referencia, tomo II, Antonio Vaquer-Aloy \& Esteve Bosch-Capdevila \& María Paz SÁnchez-GonzÁlez, Atelier, Madrid (2012).

Vaquer-Aloy, Antonio, Derecho civil de Cataluña. Derechos reales, Pedro del Pozo-Carrascosa, Antonio Vaquer-Aloy \& Esteve Bosch-Capdevila, Marcial Pons, Madrid, Barcelona, Buenos Aires, São Paulo (2012).

\section{Revistas}

Díez-PAstor, José Luis, La donación al no concebido, VI Anales de la Academia Matritense del Notariado, AAMN (1952).

Ferrer-Martín, Daniel, La incapacidad relativa para suceder del artículo 752 del Código Civil, Revista de Derecho Privado, Madrid (1951).

\section{Normatividad internacional}

Portugal, Código Civil de 1867. Texto en portugués: http://purl.pt/12145

Unión Europea, Draft Common Frame of Reference, DCFR, Study Group on a European Civil Code \& Research Group on EC Private Law (Acquis Group), based in part on a revised version of the Principles of European Contract Law. Disponible en: http://ec.europa.eu/justice/policies/civil/docs/dcfr_outline_edition_en.pdf

\section{Normatividad colombiana}

Colombia, Ley 57 de 1887, por la cual se expide el Código Civil (26 de mayo de 1873). Disponible en: http://www.alcaldiabogota.gov.co/sisjur/normas/Normal. jsp?i=39535

\section{Normatividad española}

Aragón, Ley 13/2006 o Ley de Derecho de la persona, 23 Boletín Oficial del Estado, BOE, 26 de enero de 2007. Disponible en: mhttp://www.boe.es/boe/dias/2007/01/26/ pdfs/A03713-03739.pdf 
Cataluña, Código Civil de Cataluña. Disponible en: http://civil.udg.es/normacivil/cat/ $\mathrm{ccc} / \mathrm{ES} / \mathrm{Index} \cdot \mathrm{htm}$

España, Código Civil, Real Decreto del 24 de julio de 1889, 206 Boletín Oficial del Estado, $B O E, 25$ de julio de 1889. Texto actualizado disponible en: https://www.boe.es/ buscar/act.php?id=BOE-A-1889-4763

España, Decreto de 2 de junio de 1944, por el que se aprueba con carácter definitivo el Reglamento de la organización y régimen del Notariado, 189 Boletín Oficial del Estado, BOE, 7 de julio de 1944. Texto actualizado disponible en: https://www. boe.es/buscar/act.php?id=BOE-A-1944-6578

España, Ley de 28 de mayo de 1862 o Ley Orgánica del Notariado, 80 Gaceta de Madrid, 29 de mayo de 1862. Disponible en: https://www.boe.es/datos/pdfs/BOE/1862/149/ A00001-00001.pdf

España, Ley 20/1994 o Ley de reforma del artículo 54 de la Ley de Registro Civil, 161 Boletín Oficial del Estado, BOE, 7 de julio de 1994. Disponible en: https://www. boe.es/diario_boe/txt.php?id=BOE-A-1994-15795

España, Ley 1/1996 o Ley Orgánica de Protección Jurídica del Menor, 15 Boletín Oficial del Estado, BOE, 17 de enero de 1996. Disponible en: https://www.boe.es/buscar/ doc.php?id=BOE-A-1996-1069

España, Ley 1/2000 o Ley de Enjuiciamiento Civil, LEC, 7 Boletín Oficial del Estado, $B O E, 8$ de enero de 2000. Disponible en: https://www.boe.es/buscar/act. php?id=BOE-A-2000-323

España, Ley 50/2002 o de Fundaciones, 310 Boletín Oficial del Estado, BOE, 27 de diciembre de 2002. Disponible en: https://www.boe.es/buscar/doc. php?id=BOE-A-2002-25180

España, Ley 22/2003 o Ley Concursal española, 164 Boletín Oficial del Estado, BOE, 10 de julio de 2003. Disponible en: https://www.boe.es/buscar/act. php?id=BOE-A-2003-13813

España, Ley 14/2006 o Ley sobre técnicas de reproducción humana asistida, 126 Boletín Oficial del Estado, BOE, 27 de mayo de 2006. Disponible en: https://www.boe. es/buscar/act.php?id=BOE-A-2006-9292

España, Real Decreto 316/1996, de 23 de febrero, por el que se aprueba el Reglamento de Fundaciones de Competencia Estatal, 57 Boletín Oficial del Estado, BOE, 6 de marzo de 1996. Disponible en: https://www.boe.es/boe/dias/1996/03/06/pdfs/ A08848-08859.pdf 
